\title{
Obtención y mantenimiento en cultivo de amastigotes axénicos de Leishmania peruviana y Leishmania brazilensis
}

\section{Obtaining and maintenance in cultivation of axenic amastigotes of Leishmania peruviana and Leishmania brazilensis}

\author{
Jesús Rojas Jaimes ${ }^{1, a}$, Marco Mesía Guevara ${ }^{1, b}$, Midori Chacón Cruzado ${ }^{1, c}$ \\ ${ }^{1}$ Escuela de Medicina Humana, Universidad Cientifica del Sur. Lima, Perú. \\ ${ }^{a}$ Maestro en biología molecular, ORCID: https://orcid.org/0000-0002-6910-9341 \\ ${ }^{\mathrm{b}}$ Maestro en docencia universitaria y gestión educativa, ORCID: https://orcid.org/0000-0003-4841-3624 \\ 'Estudiante de medicina humana, ORCID: https://orcid.org/0000-0001-9120-2094
}

Correspondencia:

Jesús Rojas Jaimes

jesus.rojas.jaimes@gmail.com

\section{Recibido: 5 de octubre 2020}

Aprobado: 15 de diciembre 2020

Publicación en línea: 30 de diciembre 2020

Conflictos de interés: Los autores declaran no tener conflictos de interés.

Fuente de financiamiento:

Autofinanciado

Citar como: Rojas J, Mesía M, Chacón M. Obtención y mantenimiento en cultivo de amastigotes axénicos de Leishmania peruviana y Leishmania brazilensis. An Fac med. 2020;81(3): 374-5. DOI: https:/ doi.org/10.15381/anales.v81i3.18862.

\section{An Fac med. 2020;81(3):374-5. / DOI: https://doi.org/10.15381/anales.v81i3.18862}

Sr. Editor,

Los parásitos del género Leishmania sp. adoptan las formas de promastigote y amastigote en su ciclo de vida. En busca de modelos parasitarios, un estudio utilizó amastigotes axénicos de Leishmania mexicana para probar nuevas drogas contra el parásito ${ }^{(1,2)}$. En el desarrollo de nuevas drogas es importante determinar su farmacodinamia, pudiendo actuar como metabolito secundario directamente sobre el parásito o como un compuesto modificado por la célula hospedera. En estos casos es de importancia el uso del modelo de amastigotes axénicos para conocer el efecto antiparasitario, destacando las ventajas de este modelo sobre los promastigotes que no es la fase que se encuentra en el humano y los amastigotes intracelulares que son más difíciles y costosos de mantener ${ }^{(3)}$. Se ha podido demostrar que la variación de $\mathrm{pH}$ y temperatura son claves en la conversión de promastigote a amastigote axénico ${ }^{(4,5)}$.

Presentamos los resultados de un estudio cuyo objetivo fue la obtención y sostenibilidad del cultivo de amastigotes axénicos de L. peruviana y L. braziliensis como modelos para futuros estudios sobre efectividad de drogas y fisiología del parasito.

Los promastigotes de la cepa referencial HB86 (L. peruviana) y LC53 (L. braziliensis) fueron cedidos por el Laboratorio de Patho-antígenos de la Universidad Peruana Cayetano Heredia. Los promastigotes procíclicos cedidos fueron inoculados $50 \mu \mathrm{L}$ en pocillos de microplacas de 96 en una concentración de $2,34 \times 10^{6} / \mathrm{mL}$ en $300 \mu \mathrm{L}$ de medio Schneider, suplementados con suero bovino fetal al $20 \%$ y penicilina $10000 \mathrm{U} /$ estreptomicina $10 \mathrm{mg} / \mathrm{mL}$, usando diferentes $\mathrm{pH}(4,7-5,2-5,7-6,2)$ a 35 oc, usando 3 repeticiones por cada $\mathrm{pH}$. Las lecturas se realizaron cada 7 días por 1 mes usando un conteo microscópico de parásitos teñidos por el colorante Wright, usando $10 \mu \mathrm{L}$ de cultivo fijado en lámina portaobjeto y cubriendo 100 campos.

El porcentaje de conversión por cada pocillo, usando 3 repeticiones para cada $\mathrm{pH}$, se obtuvo usando la siguiente formula: número de amastigotes observados en $10 \mu \mathrm{L} /$ número de parásitos observados en $10 \mu \mathrm{L} * 100$, con el objetivo de determinar el pH optimo donde se observó la total y mas rápida conversión de promastigotes a amastigotes axénicos. 

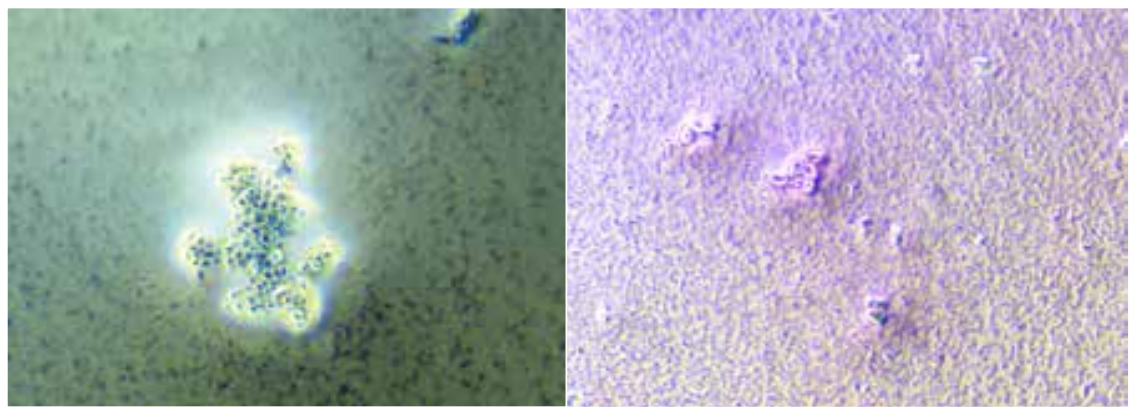

Figura 1. A la izquierda HB86 (L. peruviana) en mantenimiento a los 14 días a pH 4,7, visto al microscopio de contraste de fases, aumento 400X. A la derecha LC53 (L. braziliensis) en mantenimiento a los 14 días a $\mathrm{pH} 4,7$, visto al microscopio de contraste de fases, aumento 400X.

Para el mantenimiento se tomó $50 \mu \mathrm{L}$ de medio de cultivo con parásitos (amastigotes axénicos del pH idóneo) y se agregó en $300 \mu \mathrm{L}$ de medio con el pH idóneo sin parásitos cada 7 días. La lectura se realizó cada 7 días por 176 días.

El único medio con la variable $\mathrm{pH}$ en la que existió $100 \%$ de conversión de promastigote a amastigote axénico, tanto para HB 86 como para LC 53, fue a $\mathrm{pH}$ 4,7 , variando entre $63,7 \%$ al 70 día, $97 \%$ al día 42 y $100 \%$ al día 56\%. Manteniéndose al $100 \%$ de conversión hasta el día 176 para HB 86, 55,4\% al día 70, 96,7\% al día 14․ Para LC53, 100\% de conversión al día 56 y hasta el día 176. La carga parasitaria a $\mathrm{pH}$ 4,7 estuvo entre 11661/ $\mu \mathrm{L}$ al día 70, hasta $300 / \mu \mathrm{L}$ al día 56o para HB 86; y entre $9769,5 / \mu \mathrm{L}$ al día 70, hasta 120/ $\mu \mathrm{L}$ al día 56ㅇ. Figura 1.
Aunque un estudio previo reportó la conversión de L. braziliensis en forma axenica, no se conoce por cuánto tiempo se pudo mantener esta forma in vitro; ya que de no estar conservada esta forma parasitaria, el efecto de las drogas contra el parásito podría estar sobreestimado (3) Otro estudio previo mencionó la conversión del promastigote a amastigote axénico de Leishmania peruviana, aunque su uso fue la infección inmediata a nivel celular sin dilucidar si estos parásitos podrían ser viables en el tiempo en el medio axénico ${ }^{(1)}$. En contraste, nuestro estudio logró mantener la forma axénica de L. peruviana y $L$ braziliensis al $100 \%$ al día 56 y manteniéndose hasta por 176 días donde terminó el estudio.

Concluimos que se obtuvo amastigotes axénicos de Leishmania peruviana y
Leishmania braziliensis con una conversión del $100 \%$ de promastigotes procíclicos a amastigotes axénicos al día 56으, y que se mantuvo hasta el día 176ㅇ a pH 4,7 , a $35 \mathrm{C}^{0}$. Este hallazgo es de importancia para el estudio de drogas y la fisiología del parásito.

\section{REFERENCIAS BIBLIOGRÁFICAS}

1. González G, Castillo D, Estevez Y, Grentzinger T, Deharo E. Leishmania (Viannia) peruviana (MHOM/ $\mathrm{PE} / \mathrm{LCA08)}$ : comparison of THP-1 cell and murine macrophage susceptibility to axenic amastigotes for the screening of leishmanicidal compounds. Exp Parasitol. 2009;122(4):353-6. DOI: 10.1016/j. exppara.2009.05.005

2. Luis L, González-Luna D, Serrano ML, Orué A, Mendoza-León A. Evaluación de drogas en Leishmania sp. : Estudios moleculares y modelaje molecular de nuevos blancos. Glibenclamida: Efecto sobre la transformación in vitro de Leishmania sp. Memorias del Instituto de Biologia Experimental. 2008;5:149-152.

3. Rios YR, Otero AJ, Muñoz DL, Echeverry M, Robledo SM, Yepes MA. Actividad citotóxica y leishmanicida in vitro del aceite esencial de manzanilla (Matricaria chamomilla). Rev Colomb Cienc Quím Farm. 2008;37(2):200-211.

4. Valencia G, Vera B, Flores A, Andrade F. Obtención de cultivo axénico de amastigotes de tres cepas de Leishmania (Leishmania) mexicana a partir de promastigotes aislados de pacientes con leishmaniasis cutánea localizada en México. Rev bioméd. 1998;9(4):206-13.

5. García A. Comparación de la susceptibilidad farmacológica in vitro de amastigotes de Leishmania amazonensis en distintos tipos celulares. Recursos Educativos. 2012;4(10):16. 